\title{
Motives influencing Facebook usage as a social networking site: An empirical study using international students
}

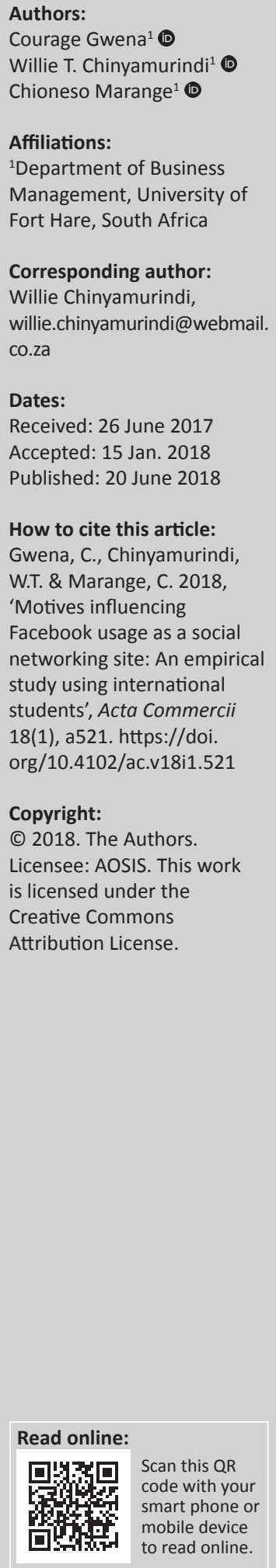

Orientation: Recent trends in the world show a growing usage of social networking sites. Research has grown in interest on understanding uses of social networking sites by different groups of people. With increasing numbers of international students being hosted by South African institutions, it is imperative that special focus should be directed towards understanding their usage of social networking sites as part of their lived experience.

Research purpose: The purpose of the study was to investigate the motives influencing Facebook usage amongst international students at a rural campus in South Africa.

Motivation for the study: Continued increase in international student enrolment at South African institutions, coupled with rising popularity of social networking sites amongst university students, has presented a new area to carry out research of this nature.

Research approach, design and method: A quantitative research approach was followed in carrying out this study. Descriptive and inferential statistics were performed to answer the research questions of the study. The respondents $(n=158)$ were international students enrolled at a rural university campus in the Eastern Cape Province of South Africa during the 2016 academic year.

Main findings: Motives for Facebook usage were found to be positively related to Facebook usage.

Practical and managerial implications: Findings of this study can assist international education practitioners to develop strategies that will aid in understanding how international students operate in the higher education context.

\section{Introduction}

Usage of social networking sites (SNSs) like Facebook, Instagram, Twitter and WhatsApp has increased globally and is playing a pivotal role in people's lives (e.g. García-domingo, Aranda \& Fuentes 2017; Hashim \& Kutbi 2015; Krasnova, Veltri, Eling \& Buxmann 2017). There are over 1 billion users of SNSs across the world, and this has led researchers to argue for continued research in how people engage with and interact through SNSs (e.g. Jin, Diego \& Chen 2013; Subramani 2015). Despite this interest on research in SNSs, many studies have mainly been confined to developed countries (e.g. DiVall \& Kirwin 2012; Ellison \& Boyd 2013; Hashim \& Kutbi 2015). In addition, there is growing interest in studies that focus on how international students use SNSs (e.g. Binsahl, Chang \& Bosua 2015; Chen \& Hanasono 2016; Rahman 2014). International students are an important cohort as they occupy a strategic advantage within institutions of higher learning (Forbush \& Foucault-Welles 2016). For instance, Chen and Hanasono (2016) argue that international students are an important cultural rent in that they add value to the countries' intellectual capital and labour force.

As international students are far away from home, they strive for channels and platforms through which they can communicate (Chen \& Hanasono 2016). As a result, these students often suffer from cultural estrangement as well as loneliness because of a deprivation of established bonds and therefore need to find ways to adjust to new conditions (Whillans \& Chen 2017). This research intends to investigate motives influencing international students' use of SNSs to meet their varying social and psychological needs. Notably, there are some studies that focus on how international students adjust in foreign countries (Chen \& Hanasono 2016; Forbush \& FoucaultWelles 2016; Whillans \& Chen 2017). However, there is little or no research that pays attention to how SNSs such as Facebook are used by international students from a South African perspective, 
yet South Africa is experiencing increased enrolment of international students (Hemis 2014). Furthermore, studies on international students (e.g. Binsahl et al. 2015; Chang et al. 2014; Chen \& Kuo 2017; Kumar, Joshi \& Sharma 2016) have been contextualised in favour of students who study mostly in urban areas. However, there appears to be neglect within the research community on understanding the experiences of international students especially at rural campuses.

\section{Social networking sites}

According to Thurairaj et al. (2015), SNSs are defined as mobile- or Internet-based social platforms created and designed to enable users to communicate, collaborate and share content across contacts and communities. Many researchers (e.g. García-domingo et al. 2017; Heerden \& Jordaan 2017; Hu, Zhao \& Huang 2015; Lu, Lin \& Lu 2016; Robertson \& Kee 2017) agree on the definition of SNSs suggested by Boyd and Ellison (2008), who defined the term as platforms that allow individual users to (1) create public and semi-public profiles within circumscribed systems, (2) choose other users with whom they can share connections and (3) observe and navigate through lists of connections and those created by others in the same system.

Currently, the most popular SNSs include Facebook, Twitter, Instagram, Snapchat and WhatsApp. Usage and development of various SNSs continue to increase across the world because of the value they have in aiding human communication (World Wide Worx \& Fuseware 2016). Notable benefits of SNSs identified by a previous study include the creation of relationships, sharing of content and opinions, entertainment and communication (Woo \& Lee 2017). Regardless of the positive side of SNS usage, concerns have emerged over their potential to be addictive, and there are also concerns about privacy of users and control of information (Jeong \& Kim 2017). This study focuses on the most used SNSs, namely, Facebook (García-domingo et al. 2017). According to Chao and Keung (2017), Facebook is one of the most popular SNSs worldwide, with 1.71 billion active users in 2016. Garcíadomingo et al. (2017) also noted that three of four global Internet users are on Facebook, possibly affirming the popularity of this SNS.

\section{Theoretical framework underpinning social networking sites usage}

This study was informed by the uses and gratifications theory (U \& GT). This theory emerged in the 1940s as a basis for studying gratifications that attracted media users (Katz, Haas \& Gurevitch 1973). In light of this theory, it is assumed that media users consider the benefits of interaction with media in solving their problems and meeting their needs (Rousseau, Eggermont \& Frison 2017). The theory also accepts that individuals from diverse backgrounds have different choices of media and that people differ in their reasons and motivations for SNS usage (Heerden \& Jordaan 2017). In line with the same view, the U \& GT therefore qualifies to be used as a theory to investigate SNSs usage amongst students of an international background. Many researchers (e.g. Chuang 2015; Froget, Baghestan \& Asfaranjan 2013; Heerden \& Jordaan 2017; Karimi, Khodabandelou \& Ahmad 2014) agree that the main motivations behind SNS use include meeting needs for the following gratifications - information search, need for entertainment, maintaining relationships, need to meet new people, need to discuss, need to share media and the need to connect.

\section{Motives influencing Facebook usage The need to meet new people}

Users of SNSs utilise them to meet new people online (Tiryakioglu \& Erzurum 2011). This is because SNSs provide tools that facilitate person-to-person interaction, resulting in possibilities of total strangers getting closer and building relationships that are an alternative to offline contacts (Binsahl et al. 2015). SNSs also present opportunities for individuals to find like-minded people with similar interests with whom they can share emotions and collaborate. In the context of education, Facebook allows students who are in the same field of study, with same interests or living in the same area to meet in online groups where they become online friends and share information (Thurairaj et al. 2015). Previous studies on the benefits of SNSs indicated that SNSs are used as an instrument to build social capital, primarily by people who are far away from their homes (e.g. Lu et al. 2016; Vincent 2015; Woo \& Lee 2017). Whillans and Chen (2017) underlined that students leaving their homes for tertiary studies lose established social connections and memberships, which possibly results in homesickness. In that case, SNS can provide consolation by providing tools to enhance one's social capital. This is revealed in the study by Xiao and Zuang (2014) who asserted that SNSs increase social capital and also facilitate meeting new people by removing physical barriers. Based on all this, the following hypothesis can be assumed:

$\mathrm{H1}_{\mathbf{o}}$ : The need to meet new people as a motive for Facebook usage has no positive relationship with the use of Facebook by international students.

H1: The need to meet new people as a motive for Facebook usage has a positive relationship with the use of Facebook by international students.

\section{The need to share and search for information}

Studies have revealed that human beings have an inborn propensity to share and seek information (Osatuyi 2013; Yazdanpanah \& Forouzani 2015). Users of SNS use them for purposes of information seeking and searching (Hashim \& Kutbi 2015). Ng et al. (2017) postulated that SNSs have transformed information dissemination and frequently become accessed knowledge resources for information seeking by users. Tse, Bridges and Srinivasan (2015) found that individuals use SNS to make inquiries about their health concerns. Similarly, a study carried out by Hamid et al. (2016) revealed that international students use SNS to search for information which enables them to adapt to new 
environments. Students also use SNS to search for information related to their academic studies (Manjunatha 2013). This was also supported by Subramani (2015), who found that students form groups on SNSs where they exchange academic information. Thus, it can be assumed that students join academic SNSs for the sole purpose of exchanging information with their classmates or people in the same field as they are. Based on this, the following hypothesis can be assumed:

$\mathbf{H} 2$ : The need to share and search information as a motive for Facebook usage has no positive relationship with the use of Facebook by international students.

H2 : The need to share and search for information as a motive for Facebook usage has positive a relationship with the use of Facebook by international students in South Africa.

\section{The need to share media}

Social networking sites have revolutionised media sharing amongst Internet users from different backgrounds the world over (Chen \& Kuo 2017). Artists, advertisers and individuals create videos, audios and pictures to express themselves or communicate with their contacts. Manasijevic et al. (2016), in a study to investigate the usage of Facebook for learning purposes, discovered that professors and students could share multimedia clips and graphical illustrations on SNSs as an alternative learning platform to the physical classroom. Rousseau et al (2017) noted that pictures are the most shared media on Facebook followed by videos. In addition, Ho and $\mathrm{Li}$ (2011) found that Chinese international students in America used Renren, a Chinese version of Facebook, to share pictures and videos with users from their home countries. Students use different SNSs to share media while abroad (Forbush \& Foucault-Welles 2016). Based on this, the following hypothesis can be assumed:

H3 : The need to share media as a motive for Facebook usage has no positive relationship with the use of Facebook by international students.

H3: The need to share media as a motive for Facebook usage has a positive relationship with the use of Facebook by international students.

\section{The need to maintain relationships}

There is a growing body of research which empirically supports that SNSs use has both negative and positive effects on associations (Lin \& Utz 2015; Rousseau et al. 2017; Schneider, Vorderer \& Kr 2016). Research utilising the affordance approach has explained how the cost of SNSs facilitates maintenance of both online and offline relationships (Ellison \& Vitak 2015). SNSs, unlike traditional means of communication, provide a cheaper and efficient communication alternative (Alassiri 2014). The affordance approach also outlines that continuations of relationships depend on what individuals do on SNSs. Chao and Keung (2017) discovered that extreme opinions on Facebook could destroy weak relationships amongst users and result in the offending party being blocked or unfriended. Regardless of the negative side of SNSs, there is overwhelming evidence to show that SNSs are a critical means to maintaining relationships (Lu et al. 2016). SNSs allow users to keep in touch with former classmates, communities and families when they are away from them (Özad 2012). Also, it has been found that communication on SNSs facilitates maintenance of a bond that exists in real life. Results of a study conducted by Özad and Uygarer (2014) revealed that there is a statistically significant relationship between the need to maintain relationships and one's use of SNSs. Therefore, based on all this, the following hypothesis can be assumed:

H4: The need to maintain relationships as a motive of Facebook usage has no positive relationship with the use of Facebook by international students.

H4: The need to maintain relationships as a motive of Facebook usage has a positive relationship with the use of Facebook by international students.

\section{The need to connect}

The advent of SNSs has enabled people to stay connected, regardless of distance, affordably. Although Baym, Zhang and Lin (2004) discovered that students prefer to communicate face-to-face, available literature indicates that SNSs have become an alternative in the absence of face-to-face interactions. Manasijevic et al. (2016) underscored the role played by SNSs in allowing users to maintain connections with former classmates, workmates, social contacts and families whom they will be living away from. Furthermore, Lai, She and Tao (2017) found that organisations with similar interests use the tag and share features to connect not only with other organisations but with their contacts as well. According to Schneider et al. (2016), SNS users use them to stay connected with close people who would not be physically present, mainly to ensure that they are not left behind and also because of the need to belong. In the same line, a recent study on a sample of 142 Chinese international students in Japan indicated that people use SNSs to stay connected as they benefit from increased social networking and psychological well-being (Chang et al. 2014). International students use SNSs to connect and stay connected with their families and former classmates from their countries of origin (Forbush \& Foucault-Welles 2016). Considering all that has been highlighted above, the following hypothesis can be assumed:

H5 $5_{0}$ : The need to stay connected as a motive for Facebook usage has no positive relationship with the use of Facebook by international students.

H5: The need to stay connected as a motive for Facebook usage has a positive relationship the use of Facebook by international students.

\section{The need for entertainment}

The U \& GT outlines that people use social media to satisfy various needs, including the need for entertainment. Entertainment is a critical need for human existence, especially amongst users of SNSs (Xiao \& Zuang 2014). Manasijevic et al. (2016) found that Facebook is widely used every day for entertainment drives by people from various backgrounds and cultures. The literature indicates that SNSs allow individual users to upload, view and download music 
videos or watch movies and share jokes (Chuang 2015). Furthermore, in a study conducted by Binsahl et al. (2015) to investigate uses of Facebook by Saudi Arabian students, it was found that $60 \%$ of the respondents indicated they used Facebook as an entertainment tool. Based on all this, the following hypothesis can be assumed:

H6: The need for entertainment as a motive for Facebook usage has no positive relationship with the use of Facebook by international students.

H6: The need for entertainment as a motive for Facebook usage has a positive relationship with the use of Facebook by international students.

\section{The need to discuss}

People use Facebook as an SNS to discuss different issues ranging from social, economic, religious and political matters (Leng \& Goh 2011). Manasijevic et al. (2016) noted that Facebook does not only facilitate communication amongst students and teachers but can also be used for class discussions. Discussions are important in education because they enable knowledge sharing amongst participants (Chen \& Kuo 2017). Özad and Uygarer (2014) discovered that people use social networking sites to satisfy the need of discussing issues affecting them both positively and negatively. The need to discuss drives people, mainly youths, to join SNSs like Facebook and form groups where they interact and engage in discussions (Asterhan \& Bouton 2017). However, the way in which these discussion groups are formed differs from one society to another (Binsahl et al. 2015). Based on all this, the following hypothesis can be assumed:

$\mathrm{H7}_{\mathrm{o}}$ : The need to discuss as a motive for Facebook usage has no positive relationship with the use of Facebook by international students.

H7: The need to discuss as a motive for Facebook usage has a positive relationship with the use of Facebook by international students.

\section{Gender differences}

Some research studies indicate that statistically significant differences exist in SNS usage by gender (Baris Horzum 2016; García-domingo et al. 2017; Krasnova et al. 2017; Rousseau et al. 2017). More precisely, researchers across the world have discovered that women users dominate the use of SNS compared to men (Leng \& Goh 2011; Lin, Featherman \& Sarker 2017; Manjunatha 2013; Xiao \& Zuang 2014). In addition, Xie et al. (2017) observed that women SNS users show greater interest in sharing content and discussing public issues compared to men. Similarly, a survey of Saudi Arabian students in Australia indicated that women users had a negative attitude towards the use of SNS to share photos because of cultural reasons, while men used social media more for sharing photos (Yazdanpanah \& Forouzani 2015). In a study to investigate social media participation amongst students in South Africa in two different years (2010 and 2012), it was discovered that $88 \%$ of the students who used SNS were undergraduates between the ages of

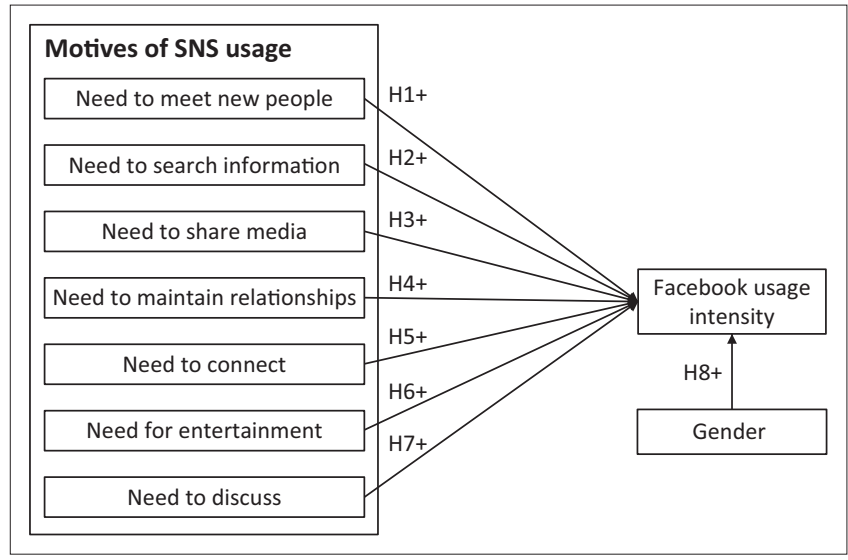

Source: Froget, L.R.J., Baghestan, G.A. \& Asfaranjan, Y.S., 2013, 'A uses and gratification perspective on social media usage and online marketing', Middle-East Journal of Scientific Research 15(1), 78-92

SNS, social networking sites.

FIGURE 1: Motives for Facebook usage.

19 and 29 years of which 53\% were women students (United Nations International Children's Emergency Fund 2012). The researcher's belief that women use SNSs more compared to men is in line with the findings of Asterhan and Bouton (2017), which discovered that teenage girls share more content on SNSs than boys do. It is also notable that the gender construct has been used as a moderator in studies on the usage of SNS (García-domingo et al. 2017; Krasnova et al. 2017; Lin et al. 2017). Based on all the above facts, the following hypothesis can be assumed:

Hypothesis 8: Women rate Facebook use higher than men.

The proposed research model is presented in Figure 1.

\section{Research methodology and design}

A quantitative research approach was chosen based on its strength in numerically measuring relationships between variables (Wiid \& Diggines 2013). Many researchers on SNS usage have followed quantitative research methods in collecting data (e.g. Manasijevic et al. 2016; Rousseau et al. 2017; Xie et al. 2017). These methods are considered reliable in describing relationships as opposed to the qualitative approach (Wiid \& Diggines 2013). Within the quantitative approach, the research was inclined towards cross-sectional design as it involved carrying out a survey on international students at a rural campus in the Eastern Cape Province of South Africa to establish the motives influencing their usage of SNSs.

\section{Sampling and data collection}

Data were collected from 158 respondents studying at a rural university campus by using a non-probability convenience sampling technique. Aself-administered survey questionnaire was distributed to international students, and informed consent was obtained before completion of the questionnaire. Completed questionnaires were collected after that for analysis. The decision to collect data from international students enrolled at a rural campus was based on the discovery that the majority of existing publications on 
international students were conducted in urban areas as in previous studies (e.g. Binsahl et al. 2015; Chen \& Hanasono 2016; Forbush \& Foucault-Welles 2016)

\section{Measures}

The questionnaire that was distributed to the participants contained four demographic questions and scales of motives for Facebook usage. The items used to measure four constructs ('use Facebook to share media', 'use Facebook to maintain relationships', 'use Facebook for entertainment' and 'use Facebook to meet people') were adapted from Nyland and Near (2007), while the scales 'use Facebook to discuss', 'use Facebook to connect' and 'Facebook usage' were adapted from Ellison, Steinfield and Lampe (2008), and lastly, the scale 'use Facebook to seek information' was adapted from Mill, Knezek and Khaddage (2014). Each scale contained some statements to which respondents were asked to indicate how much they agree or disagree with a given statement on a five-point Likert scale formulated as follows: strongly disagree, disagree, neutral, agree, strongly agree. Froget et al. (2013) used the same instrument in their study to examine the motives of social media usage by customers.

\section{Reliability and validity}

All the scales used for this study had Cronbach's alpha coefficients of 0.7 or above, thus meeting the threshold required for a measurement scale to be qualified as reliable as recommended by Nunnally (1978). Table 1 shows the used scales and their Cronbach's alpha coefficients.

\section{Data analysis and results}

Data collected were analysed using the Statistical Package for Social Sciences version 24. Descriptive statistics were used to describe the sample and Pearson's bivariate correlation coefficients (one-tailed significance criterion) were used to identify correlates of motives for usage of Facebook by international students and their intensity of Facebook use. The researchers then used simple linear regression analysis to identify the influence or relationship of the study's theoretical hypothesised variables on the usage of Facebook by international students. Each model included one motivator selected as a predictor, that is, information search, need for entertainment, maintaining relationships, need to meet new people, need to discuss, need to share media and need to connect. Tests for normality

TABLE 1: Reliability and validity of measurement scales.

\begin{tabular}{lcc}
\hline Scale items & Number of items & Cronbach's alpha \\
\hline Need to meet new people & 5 & 0.74 \\
Need to search for information & 4 & 0.87 \\
Need to share media & 3 & 0.68 \\
Need to maintain relationships & 2 & 0.75 \\
Need to connect & 6 & 0.74 \\
Need for entertainment & 3 & 0.76 \\
Need to discuss & 4 & 0.92 \\
Facebook usage & 7 & 0.84 \\
\hline
\end{tabular}

were performed using the normal plots of the standardised residuals and in assessing these the normality assumption for linear regression modelling was found satisfied in all the models. Also, assumptions dealing with outliers, homoscedasticity and autocorrelation of errors were met, suggesting a robust sample. Lastly, a one-sample $t$-test (one-tailed test) was used to find whether women rate Facebook use higher than men.

\section{Ethical considerations}

The research was guided by ethical requirements expected of researchers within the university. This was ensured through obtaining ethical clearance (reference number: CHI141SMUCO1) from the University Research Ethics Committee (UREC) at the participating university. Respondents were assured of anonymity and confidentiality and notified of their right to withdraw from the study if they felt like doing so.

\section{Results}

The results of this study were divided into descriptive and inferential statistical results. Inferential statistics were performed to determine whether the null hypotheses should be accepted or rejected.

\section{Descriptive results}

Descriptive data analysis of demographical data indicated that slightly more than half of the respondents were women constituting 50.6\% $(n=80)$, while men constituted $49.4 \%$ $(n=78)$ of the total respondents. Regarding age, the majority $(48.7 \%, n=77)$ of the respondents were aged between 21 and 25 , followed by $41.1 \%(n=65)$ aged between 26 and 30 . The age groups $31-35$ and 36 plus had $5.1 \%(n=8)$ each. With regard to the level of education, $60.1 \%(n=95)$ of the respondents were undergraduates, while $39.9 \%(n=63)$ were postgraduates. Lastly, the results reveal that the majority (54.4\%, $n=86$ ) of respondents were of Zimbabwean nationality, followed by Nigerians $(8.2 \%, n=13)$, Malawians $(6.3 \%, n=10)$ and Zambians $(5.7 \%, n=9)$. The remaining 13 nationalities that emerged in the analysis constituted $25.3 \%(n=40)$ of the respondents (see Table 2$)$.

TABLE 2: Descriptive statistics for biographical variables $(n=158)$.

\begin{tabular}{llccc}
\hline Variable & Levels & df & $f$ & aValid \% \\
\hline Gender & Men & 1 & 78 & 49.4 \\
& Women & - & 80 & 50.6 \\
Age of respondents & 21-25 years & 3 & 77 & 48.7 \\
& 26-30 years & - & 65 & 41.1 \\
& 31-35 years & - & 8 & 5.1 \\
& 36+ years & - & 8 & 5.1 \\
Level of education & Undergraduate & 1 & 95 & 60.1 \\
\multirow{4}{*}{ Nationality } & Postgraduate & - & 63 & 39.9 \\
& Zimbabwean & 16 & 86 & 54.4 \\
& Nigerian & - & 13 & 8.2 \\
& Zambian & - & 9 & 5.7 \\
& Malawian & - & 10 & 6.3 \\
& Others & - & 40 & 25.3 \\
\hline
\end{tabular}

$\mathrm{df}$, degrees of freedom, $f$, f-frequency.

a, adjusted (valid) percentages excluding missing observations. 


\section{Inferential statistics results}

Correlation analysis and simple regression analysis were performed to test the main hypotheses of the study.

\section{Correlation analysis}

Pearson's correlation analysis gave preparatory decomposition into the study and its theoretical constructs. This was necessary to check whether there was a linear relationship in the data which allowed for a simple linear regression analysis. Table 3 shows the Pearson product-moment correlations $(r)$ and significance probabilities between motivators and Facebook use. These results suggest that Facebook users had moderate positive significant relationships with most of the motivators.

\section{Simple linear regression analysis}

To assess the statistical significance of the influence of the Facebook use motivators on the use of Facebook by international students, it is necessary to use simple linear regression models to test the hypothesised frameworks. The results of the simple linear regression models are presented in Table 4.

To determine whether the different Facebook use motivators exert any positive influence on Facebook use amongst international students, simple linear regression models were examined. Separate motivators were modelled as explanatory or predictor variables, and this resulted in each of these giving statistically significant models (all $p<0.05$ ). The model fit and model summary statistics are presented in Table 4 . From these models, the use of Facebook for entertainment explained the least amount of the variation in Facebook use $\left(R^{2}=0.073\right)$, while the use of Facebook for discussion accounted for a

TABLE 3: Pearson product-moment correlations $(r)$ and significance probabilities $(p)$ for relations of motivators and Facebook use.

\begin{tabular}{lcc}
\hline Facebook use motivators & $r$ & $p$ \\
\hline Facebook use to meet people & 0.417 & $0.000^{*}$ \\
Facebook use for entertainment & 0.270 & $0.000^{*}$ \\
Facebook use to maintain relationships & 0.332 & $0.000^{*}$ \\
Facebook use for connecting & 0.481 & $0.000^{*}$ \\
Facebook use to share media & 0.439 & $0.000^{*}$ \\
Facebook use for discussion & 0.563 & $0.000^{*}$ \\
Facebook use for information & 0.416 & $0.000^{*}$ \\
\hline
\end{tabular}

$*$, correlation is remarkable when the significant level is 0.01 (one-tailed test). significantly greater amount of variation $\left(R^{2}=0.317\right)$ in the dependent variable (Facebook use). The Durbin-Watson statistic for all models is between the two critical values of $1.5<d<2.5$ and therefore we can assume that there is no firstorder linear autocorrelation in the residuals. The parameter estimates of the resultant models, both the constant terms Beta $\left(\beta_{0}\right)$ and the main effects $\left(\beta_{1}\right)$, are all statistically significant (all $p<0.05)$. As our $\beta_{1}$ coefficients are all positive and significant, there is sufficient evidence at $5 \%$ level of significance to reject the null hypothesis for all the hypothesised frameworks and conclude that Facebook use motivators exert a positive influence on Facebook use amongst international students.

\section{One-samples $t$-test}

A one-sample $t$-test was run to determine whether women rate Facebook use higher than men who rated a mean score of 3.8718 from a scale of 1 (Strongly Disagree) to 5 (Strongly Agree). Facebook intensity scores were approximately normally distributed as the Q-Q plots showed that the points were diagonal and there were no outliers in the data, as assessed by inspection of a boxplot. From the results in Table 5, it is clear that the mean Facebook use score for women $($ mean $=3.71$, standard deviation $[S D]=0.68$ ) was significantly lower than that for men (mean $=3.87, \mathrm{SD}=0.74)$. A statistically significant difference of $0.15\{[95 \%$ confidence interval (CI), 0.01 to 0.31], $t(79)=-1.031, p=0.021\}$ was established. Thus, there is sufficient evidence at $5 \%$ level of significance to conclude that women international students' rate Facebook use lower than their male counterparts. This finding is however not in the hypothesised direction, a case of unexpected results.

The summary of the hypotheses is presented in Table 6 .

\section{Discussion}

This study was carried out with the aim of establishing motives of Facebook usage amongst international students enrolled at a rural university campus. Results show that there is a positive relationship between the need to discuss and Facebook usage. This finding, together with the discovery that the majority $(48.7 \%)$ of respondents were aged between 21 and 25 years, supports the findings of a recent study conducted by Binsahl et al. (2015), which established that the

TABLE 4: Simple linear regression model fit statistics, model summary statistics and parameter estimates for Facebook use motivators on Facebook use.

\begin{tabular}{|c|c|c|c|c|c|c|}
\hline \multirow[t]{2}{*}{ Predictor variable } & \multicolumn{2}{|c|}{ Model fit } & \multicolumn{2}{|c|}{ Model summary } & \multicolumn{2}{|c|}{$\begin{array}{c}\text { Parameter estimates } \\
\text { (Unstandardised coefficients) }\end{array}$} \\
\hline & $\boldsymbol{F}$ & Sig. & $R^{2}$ & DW & $\beta_{0}(t$-value, Sig.) & $\beta_{1}(t$-value, Sig.) \\
\hline Use to meet people & 32.650 & $0.000 *$ & 0.174 & 1.740 & $2.424(9.886,0.000)^{*}$ & $0.392(9.886,0.000)^{*}$ \\
\hline Use for relationships & 19.298 & $0.000 *$ & 0.110 & 1.629 & $2.130(5.575,0.000)^{*}$ & $0.383(4.393,0.000)^{*}$ \\
\hline Use for connecting & 46.907 & $0.000^{*}$ & 0.231 & 1.874 & $2.286(10.137,0.000)^{*}$ & $0.419(6.849,0.000) *$ \\
\hline Use to share media & 37.155 & $0.000^{*}$ & 0.192 & 1.706 & $2.879(18.184,0.000)^{*}$ & $0.315(6.095,0.000)^{*}$ \\
\hline Use for information & 32.654 & $0.000 *$ & 0.173 & 1.869 & $2.350(9.123,0.000)^{*}$ & $0.367(5.714,0.000)^{*}$ \\
\hline
\end{tabular}

Note: Independent variables: constant, Facebook use motivators; dependent variable: Facebook use. DW is the Durbin-Watson test for autocorrelation of residuals in the linear regression models. *, significant fit.

$F$, is the variation between sample means; Sig., significance; $\mathrm{R}_{2}$, a statistical measure of how close the data are to the fitted regression line; DW, Durbin Watson statistic; $\beta$, Beta; $t$-value, the coefficient divided by its standard error. 
TABLE 5: One-samples $t$-test for mean gender differences on Facebook use.

\begin{tabular}{|c|c|c|c|c|c|c|}
\hline \multirow[t]{2}{*}{ Study variable } & \multirow[t]{2}{*}{ Gender } & \multirow[t]{2}{*}{ Mean (SD) } & \multicolumn{4}{|c|}{ Test value $=\mathbf{3 . 8 7 1 7}$} \\
\hline & & & $t$ & df & Sig. (1-tailed) & Mean Diff (Cl) \\
\hline \multirow[t]{2}{*}{ Facebook use } & Men & $3.87(0.74)$ & -1.031 & 79 & 0.021 & $-0.15721(-0.31,-0.01)$ \\
\hline & Women & $3.71(0.68)$ & & & & \\
\hline
\end{tabular}

Note: $n($ men $)=78$ and $n$ (women $)=80$.

$\mathrm{Cl}$, confidence interval; SD, standard deviation Sig., significance; $t$, the coefficient divided by its standard error; df, degrees of freedom.

TABLE 6: Summary of the hypotheses results.

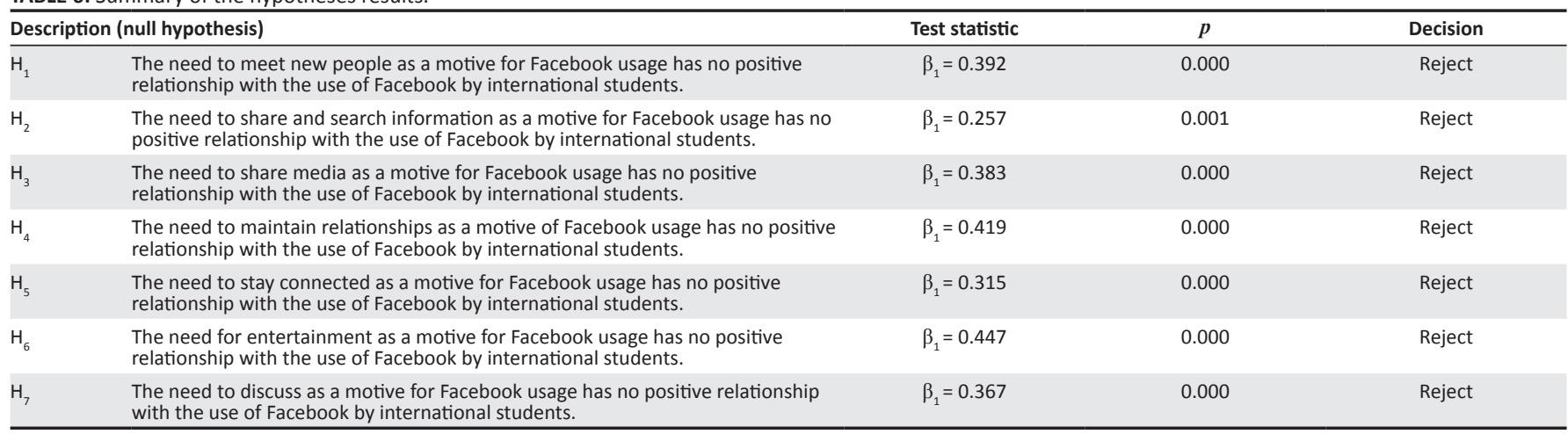

need to discuss drives people, mainly youths, to join SNSs such as Facebook to discuss various topics with people with similar interests. Facebook features such as reply and comment options allow for exchanges between contacts or users in a discussion (Manasijevic et al. 2016).

The results of this study also established that the need to meet new people positively influences Facebook usage amongst international students. This result concurred with those of previous research that discovered that users of SNSs such as Facebook and Twitter use them to meet new people online (Tiryakioglu \& Erzurum 2011). This is so because Facebook allows students who are in the same field of study, with similar interests or living in the same area to meet in online groups where they become online friends, thereby building social capital to compensate for the loss of bonds because of change of environment (Thurairaj et al. 2015). Chao and Keung (2017) pointed out that Facebook provides features sufficient for relationship development such as messaging, liking and commenting options. Furthermore, it also offers cues like mutual friends and common interests, which can serve as a guide as to whether to establish a friendship or connection based on common grounds (Whillans \& Chen 2017). The identification information on Facebook profiles provides the social lubricant necessary for the establishment of new friendships and associations.

Moreover, the results of this study revealed that the need to share and search for information had a positive relationship with Facebook usage amongst international students, which is in agreement with previous studies (e.g. Baris Horzum 2016; Chao \& Keung 2017; García-domingom et al. 2017) that established a positive and significant relationship between Facebook usage and information search. Also, the existing literature on students' use of SNSs shows that students use SNSs like Facebook, Twitter and Instagram to search for information which enables them to adapt to new environments (Hamid et al. 2016; Manjunatha 2013).
Furthermore, the results of this study proved that the need to share media positively affects Facebook usage amongst international students, which is in agreement with a recent study carried out by Ho and Li (2011) where the authors found that Chinese international students in the United States of America used Renren, a Chinese version of Facebook, to share pictures and videos with users from their home country. The results of this study, like the previous ones, affirm the assertion that SNSs are tools used by millions of people to share media, thus supporting the researcher's initial assumption that the need to share media positively influences Facebook usage (Forbush \& Foucault-Welles 2016).

The research also established that international students' need to maintain relationships positively affects Facebook usage. These results are in congruence with those of a related study conducted by Özad (2012), which revealed that the need to maintain relationships influences SNS usage. In addition, results of a study conducted by Özad and Uygarer (2014) also revealed that there is a statistically significant relationship between the need to maintain relationships and one's use of SNSs. The physical distance that is created when international students move from one country to another threatens the existence of their established relationships and friendships. For a relationship to remain intact, there has to be consistent and effective communication between the concerned parties. Facebook provides a platform for people to affordably interact and share videos, audios and pictures, thereby making geographic distance a lesser obstacle in keeping relationships alive (Rousseau et al. 2017).

The research also established that the need to stay connected intensifies the use of Facebook amongst international students. This means that the more international students want to stay connected, the more they use Facebook. These results corroborate an observation made by Rahman (2014) who noted that international students, being far away from home, need to constantly communicate with their friends 
and families around the world. Even though Baym et al. (2004) discovered that students prefer to communicate faceto-face, findings of this research concur with those of Chen and Hanasono (2016) who established that distance and cost barriers in international communications necessitate the utilisation of SNSs like Facebook as these are cheap and more convenient to the students than the traditional means of communication such as voice calls. These results were similar to those of a previous study conducted on a sample of 142 Chinese international students in Japan which indicated that the need to stay connected positively influences Facebook usage (Chang et al. 2014).

The need for entertainment was identified as having a positive relationship with Facebook usage. The findings of this research showed that the desire for entertainment amongst international students influences them to increase their usage of Facebook. The content uploaded and posted on Facebook also provides entertainment to users. Games, videos, photos and in general status updates are described as a source of amusement by users of Facebook (Xiao \& Zuang 2014). Similar findings were reported by Binsahl et al. (2015) after carrying out a study to investigate uses of Facebook by Saudi Arabian students in Australia.

Asterhan and Bouton (2017) noted that the need to discuss drives people, mainly youths, to join SNSs like Facebook and form groups where they interact and engage in various discussions. This research established that international students use Facebook to discuss. As posited by Leng and Goh (2011), people use Facebook as an SNS to discuss different issues ranging from social, economic, religious, political and academic issues.

On testing whether there is a difference in use of Facebook amongst various genders, the research revealed that there is a notable difference between women and men with regard to the use of Facebook. This result contradicted those of previous studies (Leng \& Goh 2011; Manjunatha 2013; Xiao \& Zuang 2014) by revealing that men rate the use of SNSs higher compared to women. Existing research shows that women use SNSs more than men because women always solicit their peers' and relatives' opinions. For instance, results from a study by Rousseau et al. (2017), which investigated the role of Facebook on body dissatisfaction, revealed that women are more susceptible to influences of people in their network and tend to make more comparisons with their contacts, thus resulting in more women using SNSs like Facebook than men. This study, however, points to men rating SNS usage more than women.

\section{Theoretical implications}

The key contribution of this study is that it answered the questions on the type of relationship that exists between uses of Facebook and Facebook usage amongst international students enrolled at a rural university campus. This was an area in which no or few studies have been conducted in the context of South Africa.
The results of this research also revealed that there are similarities with results of previous studies carried out in a different cultural setting (Osatuyi 2013; Yazdanpanah \& Forouzani 2015) about how different functions of Facebook are related to Facebook usage. This study revealed that there is a positive relationship between uses of Facebook and the Facebook usage, in the same way as existing research results.

Furthermore, this study established that men enrolled as international students rate Facebook usage more than their female counterparts. This result is in contrast with previous studies (Leng \& Goh 2011; Manjunatha 2013; Xiao \& Zuang 2014) which found that there was a considerable difference in the usage of Facebook by gender. Lastly, the results of this research help to further the understanding of SNSs usage and behaviour of international students as a population group. The research zoomed into the usage of Facebook as an SNS amongst international students enrolled at a rural campus from a South African perspective. This filled a gap that exists concerning international students in South Africa.

\section{Contribution of the study}

By providing information on the motives influencing Facebook usage, this study can help other SNS developers to enhance features on their SNSs to promote their usage. More customised features can be developed to cater to the needs of homogeneous groups such as international students. Customisation is important because according to Heerden and Jordaan (2017), people from various backgrounds may differ in their reasons and motivations for SNS use. Existing literature indicates that usage of SNSs differs by age and gender (United Nations International Children's Emergency Fund 2012). As this research found that international students use Facebook for entertainment, SNS developers can also use this information as a basis for enhancing and developing entertainment features to promote the use of their SNSs as well as make them enjoyable to use. Entertainment is an integral part of human life and contributes towards the psychological needs of humans (Froget et al. 2013). Administrators operating organisational Facebook pages may also use this information to come up with strategies that incorporate entertainment to attract international students to their Facebook or other SNS accounts.

Moreover, this study may also assist South African universities to come up with ways in which they can improve interaction within international student communities through SNSs because these sites facilitate online interaction amongst users (Gracia-domingo et al. 2017). The study revealed that international students use Facebook to search for information. International students form an integral part of the university community, and effective communication with international students through Facebook will increase their satisfaction (Forbush \& Foucault-Welles 2016). Therefore, university departments that interact with international students stand to benefit from this study in coming up with informed social media strategies. 
Furthermore, the results of this study can be of great use to providers of non-academic services which are important to international students. These non-academic services include medical aid providers, accommodation owners, transport operators and entertainers. This research revealed that international students use SNSs like Facebook to search for information; therefore, service providers need to put platforms where international students can search for information. Chang et al. (2014) discovered that international students adapt to the host countries' environment through frequently visiting official websites for information purposes. Therefore, there is a need for service providers to disseminate information from platforms such as Facebook where there is high traffic of international students.

Social networking site operators can also benefit from the findings of this research which revealed that the need to connect positively influences Facebook usage. According to Schneider et al. (2016), students need to stay connected with their families and their established social contacts. Facebook operators should, therefore, put in place features or platforms which allow international students to connect with their friends and loved ones back home as well make these easy to use in maintaining existing relationships. Also, this research can be used as a basis for further research by other researchers who are interested in SNSs and their uses.

\section{Limitations of the study}

Regarding limitations of the study, it should be pointed out that the research was confined to a single university out of 26 universities available in South Africa. The results would have been more conclusive and generalisable to the entire population if the study had taken samples from more universities.

Also, data were collected through the convenience sampling method where data were collected from respondents accessible and convenient to the researcher. This means that results from descriptive analysis of biographical data might be biased and need to be considered with caution. Moreover, this study was conducted within less than a year. Limited time of carrying out the research might have negatively impacted the quantity of data collected. It would have been possible to collect more data had there been more time for the research process. Collecting more data could have enhanced the quality of the research.

Another weakness of this study is that the data were collected from a small sample of 158 international students. Results show that Zimbabweans were the dominant respondents to the research, and this might have influenced the type and quality of data collected. A large sample would have improved the quality of research results and their implications on generalisability.

Moreover, this study followed a quantitative research approach and could not give any insights as to why considerable differences exist between men and women about Facebook usage. A qualitative research would have helped to establish why differences exist along gender lines amongst international students. Regardless of its shortcomings, the study results added information to the existing literature on the topic of SNSs usage and international students. This can also serve as a basis for further research by researchers interested in the same area of study.

\section{Recommendations for further study}

Further research has to be carried out in other universities to make it possible to arrive at conclusions that are generalisable to the entire population of international students in South Africa. Also, future studies should follow a qualitative research approach to gain more insights into the motives influencing Facebook usage. Qualitative studies will allow for better understanding of why there are considerable differences between different genders in Facebook usage amongst international students.

Further research should be carried out to investigate the motives influencing Facebook usage amongst students from the same country. Another possible path for future research studies is to carry out a more in-depth analysis of the characteristics of international students who use Facebook and other SNSs. This will assist in confirming or rejecting observations made in the current study.

\section{Conclusion}

Motives influencing Facebook usage amongst international students were investigated, and their relationships with Facebook usage were tested. Through the findings of this research, strategies can be suggested to assist not only the students but also administrators within the university community. The study attests to the popularity of SNSs such as Facebook as an outlet of social and psychological expression in view of a situation such as studying in a foreign land.

\section{Acknowledgements}

The authors acknowledge the input of the anonymous reviewers which helped improve their work.

\section{Competing interests}

The authors declare that they have no financial or personal relationships that may have inappropriately influenced them in writing this article.

\section{Authors' contributions}

C.G. authored the collected the data as part of his honours studies. He also authored the article. W.T.C. assisted in the authoring of the article and supervised C.G. for his honours studies. C.M. assisted in analysing the data. 


\section{References}

Alassiri, A.A., 2014, 'Usage of social networking sites and technological impact on the interaction-school of applied physics', International Journal of Humanities and Social Science 4(4), 46-61.

Asterhan, C.S.C. \& Bouton, E., 2017, 'Teenage peer-to-peer knowledge sharing through social network sites in secondary schools', Computers \& Education 110 16-34. https://doi.org/10.1016/j.compedu.2017.03.007

Baris Horzum, M.B., 2016, 'Examining the relationship to gender and personality on the purpose of Facebook usage of Turkish university students', Computers in Human Behavior 64, 319-328. https://doi.org/10.1016/j.chb.2016.06.010

Baym, N.K., Zhang, Y.B. \& Lin, M.C., 2004, 'Social interactions across media: Interpersonal communication on the internet, face-to-face, and the telephone', New Media \& Society 6(3), 299-318. https://doi.org/10.1177/1461444804041438

Binsahl, H., Chang, S. \& Bosua, R., 2015, 'Identity and belonging: Saudi female international students and their use of social networking sites', Journal of Migration and Culture 6(1), 81-102. https://doi.org/10.1386/cjmc.6.1.81_1

Boyd, D.M. \& Ellison, N.B., 2008, 'Social networking sites: Definition, history, and scholarship', Journal of Computer-Mediated Communication 13, 210-230. https:// doi.org/10.1111/j.1083-6101.2007.00393

Chang, S., Lin, Y., Lin, C., Chang, H. \& Chong, P.P., 2014, 'Promoting positive psychology using social networking sites: A study of new college entrants on Facebook International Journal of Environmental Research and Public Health 1, 4652-4663. https://doi.org/10.3390/ijerph110504652

Chao, C. \& Keung, N., 2017, 'Predicting social capital on Facebook: The implications of use intensity, perceived content desirability, and Facebook-enabled communication practices', Computers in Human Behavior 72, 259-268. https://doi.org/10.1016/j. chb.2017.02.058

Chen, L. \& Hanasono, L.K., 2016, 'The effect of acculturation on Chinese International students usage of Facebook and Renren', China Media Research 12(1), 46-60.

Chen, P. \& Kuo, S., 2017, 'Technological forecasting \& social change innovation resistance and strategic implications of enterprise social media websites in Taiwan resistance and strategic implications of enterprise social media websites in Taiwan Change 118, 55-69. https://doi.org/10.1016/j.techfore.2017.02.002

Chuang, Y., 2015, 'Towards an understanding of uses and gratification theory and sense of virtual community on knowledge sharing in online game communities', International Journal of Humanities and Social Science 5(6), 234-255. https://doi. org/10.7763/IJIET.2015.V5.552

DiVall, M.V. \& Kirwin, J.L., 2012, 'Using Facebook to facilitate course-related discussion between students and faculty members', American Journal of Pharmaceutical Education 76(2), 23-33. https://doi.org/10.5688/ajpe76232

Ellison, N.B. \& Boyd, D., 2013, 'Sociality through social network sites', in W.H. Dutton (ed.), The Oxford handbook of internet studies, pp. 71-85, Oxford University Press, Oxford.

Ellison, N.B., Lampe, C. \& Steinfield, C., 2008, 'Social capital, self-esteem, and use of online social network sites. A longitudinal study', Journal of Applied Developmental Psychology 8(23), 112-127.

Ellison, N.B. \& Vitak, J., 2015, 'Social network site affordances and their relationship to social capital processes', in S.S. Sundar (ed.), The handbook of the psychology of communication technology, Wiley-Blackwell, Boston, MA.

Forbush, E. \& Foucault-Welles, B., 2016, 'International journal of intercultural relations social media use and adaptation among Chinese students beginning to study in the United States', International Journal of Intercultural Relations 50, 1-12. https://doi.org/10.1016/j.ijintrel.2015.10.007

Froget, L.R.J., Baghestan, G.A. \& Asfaranjan, Y.S., 2013, 'A uses and gratification perspective on social media usage and online marketing', Middle-East Journal of Scientific Research 15(1), 78-92.

García-Domingo, M., Aranda, M. \& Fuentes, V.M., 2017, 'Facebook use in university students: Exposure and reinforcement search', Procedia - Social and Behavioral Sciences 237, 249-254. https://doi.org/10.1016/j.sbspro.2017.02.071

Hamid, S., Bukhari, S., Ravana, S.D., Norman, A.A. \& ljab, M.T., 2016, 'Role of social media in information-seeking behaviour of international students: A systematic literature review', Aslib Journal of Information Management 68(5), 643-666. https://doi.org/10.1108/AJIM-03-2016-0031

Hashim, K. \& Kutbi, I., 2015, 'Perceptions of social media impact on students' social behavior: A comparison between arts and science students', International Journal of Education and Social Science 2(4), 122-131.

Heerden, V.G. \& Jordaan, Y., 2017, 'Online privacy-related predictors of Facebook usage intensity', Computers in Human Behavior 70, 90-96. https://doi.org/ 10.1016/j.chb.2016.12.048

Hemis, 2014, viewed 05 June 2016, from https://chet.org.za./data/sahe-open-data

Ho, K.T. \& Li, C., 2011, 'From privacy concern to uses of social network sites: A cultural comparison via user survey', Proceedings - 2011 IEEE International Conference on Privacy, Security, Risk and Trust and IEEE International Conference on Social Computing, PASSAT/SocialCom, 2011, pp. 457-464.

Hu, C., Zhao, L. \& Huang, J., 2015, 'Computers in human behavior achieving selfcongruency? Examining why individuals reconstruct their virtual identity in communities of interest established within social network platforms', Computers in Human Behavior 50, 465-475. https://doi.org/10.1016/j.chb.2015.04.027

Jeong, Y. \& Kim, Y., 2017, 'Privacy concerns on social networking sites: Interplay among posting types, international and audiences', Computers in Human Behavio 69, 302-310.https://doi.org/10.1016/j.chb.2016.12.042
Jin, L., Diego, S. \& Chen, Y., 2013, 'Understanding user behaviour in online social networks: A survey', IEEE Communications Magazine 17, 144-150.

Katz, E., Haas, H. \& Gurevitch, M., 1973, 'On the use of the mass media for important things', American Sociological Review 38, 164-181. https://doi.org/10.2307/ 2094393

Karimi, L., Khodabandelou, R. \& Ahmad, M., 2014, 'Applying the uses and gratification theory to compare higher education student's motivation for using social networking sites: Experiences from Iran', Computers in Human Behavior 5(12), 1-5.

Krasnova, H., Veltri, N.F., Eling, N. \& Buxmann, P., 2017, 'Journal of strategic information systems why men and women continue to use social networking sites: The role of gender differences', Journal of Strategic Information Systems 4(8), 1-19.

Kumar, S., Joshi, A. \& Sharma, H., 2016, 'A multi-analytical approach to predict the Facebook usage in higher education', Computers in Human Behavior 55, 340-353. https://doi.org/10.1016/j.chb.2015.09.020

Lai, C., She, B. \& Tao, C., 2017, 'Connecting the dots: A longitudinal observation of relief organizations representational networks on social media', Computers in Human Behavior 74, 224-234. https://doi.org/10.1016/j.chb.2017.04.037

Leng, K. \& Goh, S., 2011, 'An exploration of Social Networking Sites (SNS) adoption in Malaysia using Technology Acceptance Model (TAM), Theory of Planned
Behavior (TPB) and intrinsic motivation', Journal of Internet Banking and Behavior (TPB) and
Commerce 16(2), 1-18.

Lin, X., Featherman, M. \& Sarker, S., 2017, 'Information \& management understanding factors affecting users 'social networking site continuance: A gender difference perspective', Information \& Management 54(3), 383-395. https://doi.org/ perspective', Information

Lu, H., Lin, K. \& Lu, H., 2016, 'Why people use social networking sites: An empirical study integrating network externalities and motivation theory', Computers in Human Behavior 27, 1152-1161.

Lin, R. \& Utz, S., 2015, 'The emotional responses of browsing Facebook: Happiness, envy, and the role of tie strength.' Computers in Human Behavior 52, 29-38. https://doi.org/10.1016/j.chb.2015.04.064

Manasijevic, D., Zivkovic, D., Arsi, S. \& Milosevic, I., 2016, 'Computers in human behaviour exploring students' purposes of usage and educational usage of Facebook', Computers in Human Behavior 60,441-450. https://doi.org/10.1016/j. chb.2016.02.087

Manjunatha, S., 2013, 'The usage of social networking sites among the college students in India', International Research Journal of Social Science 2(5), 15-21.

Mill, L.A., Knezek, G. \& Khaddage, F., 2014, 'Information seeking, Information sharing and going mobile. Three bridges to informal learning,' Computers in Human Behavior 32, 324-334. https://doi.org/10.1016/j.chb.2013.08.008

Ng, J.P., Tarazi, N., Byrne, D.P., Baker, J.F. \& Mccabe, J.P., 2017, 'Scoliosis and the socia media: Facebook as a means of information exchange', Spine Deformity 5(2), 102-108. https://doi.org/10.1016/j.jspd.2016.11.003

Nunnally, J.C., 1978, Psychometric theory, McGraw-Hill Book Company, New York.

Nyland, R. \& Near, C., 2007, 'Jesus is my friend: Religiosity as a mediating factor in internet social networking use', AEJMC Midwinter Conference - Proceedings, Reno, Navada, 23rd-24th February.

Osatuyi, B., 2013, 'Information sharing on social media sites', Computers in Human Behavior 29(13), 2622-2631. https://doi.org/10.1016/j.chb.2013.07.001

Özad, B., 2012, Tertiary students' attitudes towards using SNS, Paper presented at the International Conference on Communication, Media, Technology and Design, Istanbul, Turkey

Özad, B.E. \& Gulen, U., 2014, 'Attachment needs and social networking sites', Journa of Social Behavior and Personality 42(Suppl), 43-52. https://doi.org/10.2224/ sbp.2014.42.0.S43

Özad, E.B. \& Uygarer, G., 2014, 'Social behaviour and personality: Attachment need and social networking sites', Computers in Human Behavior 42, 43-52.

Rahman, N., 2014, 'The usage and online behavior of social networking sites among international students in New Zealand', The Journal of Social Media in Society 3(2), $669-670$.

Robertson, B.W. \& Kee, K.F., 2017, 'Social media at work: The roles of job satisfaction, employment status, and Facebook use with co-workers', Computers in Human Behavior 70, 191-196. https://doi.org/10.1016/j.chb.2016.12.080

Rousseau, A., Eggermont, S. \& Frison, E., 2017, 'The reciprocal and indirect relationships between passive Facebook use, comparison on Facebook and adolescents' body dissatisfaction', Computers in Human Behavior 73, 336-344. https://doi.org/10.1016/j.chb.2017.03.056

Schneider, F.M., Vorderer, P. \& Krömer, N., 2016, 'Permanently online permanently connected: Explorations into university students' use of social media and mobile smart devices', Computers in Human Behavior 63, 694-703. https://doi.org/ 10.1016/j.chb.2016.05.085

Subramani, R., 2015, 'The academic usage of social networking sites by the university students of Tamil Nadu R. Subramani, Periyar University, India', Online Journal of Communication and Media Technologies 5(3), 162-176.

Thurairaj, S., Hoon, E.P., Roy, S.S., Fong, P.W., Tunku, U., Rahman, A. et al., 2015, 'Reflections of students' language usage in social networking sites: Making or marring academic English', Universiti Tunku Abdul Rahman 13(4), 302-316.

Tiryakioglu, F. \& Erzurum, F., 2011, 'Use of social networks as an education tool', Contemporary Educational Technology 2(2), 135-150. 
Tse, C.K., Bridges, S.M. \& Srinivasan, D.P., 2015, 'Social media in adolescent health literacy education: A pilot study', Journal of Medical Research 2015, 4-18. https:// doi.org/10.2196/resprot.3285

United Nations International Children's Emergency Fund, 2012, Study on South African young people on mobiles: South African mobile generation, viewed 20 May 2017, from http://www.unicef.org/2012/index.htm

Vincent, C., 2015, 'The impact of participating social networking sites: A study of university students in Hong Kong and Wuhan in China Vincent Cho, The Hon Kong Polytechnic University, Hong Kong', Online Journal of Communication and Media Technologies 5(2), 181-213.

Whillans, A.V. \& Chen, F.S., 2017, 'Facebook undermines the social belonging of firs year students', Personality and Individual Differences 4, 10-13. https://doi.org/ 10.1016/j.paid.2017.03.043

Wiid, J. \& Diggines, C., 2013, 'Research design and proposal', in W. Prillaid (ed.), Marketing research, 2 nd edn., pp. 53-328, Juta and Company Ltd, Cape Town.
Woo, S. \& Lee, J., 2017, 'Telematics and informatics a comparative study of KakaoStory and Facebook: Focusing on use patterns and use motives', Telematics and Informatics 34(1), 220-229. https://doi.org/10.1016/j.tele.2016.04.013

World Wide Worx \& Fuseware, 2016, South African social media landscape 2016 viewed 09 May 2017, from http://www.worldwideworx.com/wp-content/uploads/ 2016/11/Exec-Summary-Social-Media-2016.pdf

Xiao, Q. \& Zuang, W., 2014, 'Using social networking sites: What is the big attraction? Exploring a mediated moderation relationship', Journal of Internet Commerce 5(3), 45-64. https://doi.org/10.1080/15332861.2014.898441

Xie, Y., Qiao, R., Shao, G. \& Chen, H., 2017, 'Telematics and informatics research on Chinese social media users' communication behaviors during public emergency events', Telematics and Informatics 34(3), 740-754. https://doi.org/10.1016/j.tele. 2016.05 .023

Yazdanpanah, M. \& Forouzani, M., 2015, 'Application of the theory of planned behaviour to predict Iranian students' intention to purchase organic food', Journa of Cleaner Production 107, 342-352. https://doi.org/10.1016/j.jclepro.2015.02.071 